ORIGINAL RESEARCH ARTICLE

\title{
Self-Efficacy Mediates the Association between Partner Trust and Condom Usage among Females but not Males in a Kenyan Cohort of Orphan and Vulnerable Youth
}

\author{
Michael L. Goodman ${ }^{1,2,3} *$, Melissa B. Harrell ${ }^{3}$, Stanley Gitari ${ }^{4}$, Philip H. Keiser ${ }^{1}$ and Lauren \\ A. Raimer-Goodman ${ }^{1,2}$
}

University of Texas Medical Branch; Galveston, TX $77551^{1}$; Sodzo International; Houston, TX $77002^{2}$; University of Texas School of Public Health; Houston, TX $77030^{3}$; Maua Methodist Hospital; Meru County, Kenya ${ }^{4}$

*For Correspondence: Email: mlgoodman15@gmail.com; Phone: +1.713.292.6588

\begin{abstract}
Continuing gains against incidence of HIV and other unwanted consequences of unprotected sex requires deeper understanding of characteristics of condom usage among sexually active youth. The present study assesses whether partner trust predicts condom usage, and whether potential associations were mediated by general self-efficacy, among a cohort of sexually active adolescents in Meru County, Kenya. We also sought to discover associations between socio-economic status, psychological resilience and partner trust to increase understanding of trust towards one's intercourse partner. Mediation analyses, stratified by gender, reveal that condom usage is predicted by self-efficacy and partner trust among females but not males. Higher psychological resilience predicts lower partner trust among both genders. Partner trust was lower among female respondents who were not literate, but did not significantly vary by literacy among males. Reported previous monthly earnings were not significantly associated with partner trust among males or females. The present findings support further study on partner trust, and its association with protective sex behaviors. Further, interventions targeting condom usage among females may benefit from actions to increase awareness of partner sexual behavior and increasing self-efficacy. (Afr $J$ Reprod Health 2016; 20[2]: 94-103).
\end{abstract}

Keywords: condom use; self-efficacy; orphans and vulnerable children; Kenya

\section{Résumé}

La poursuite des gains contre l'incidence du VIH et d'autres conséquences non désirés des rapports sexuels non protégés nécessite une meilleure compréhension des caractéristiques de l'utilisation du préservatif chez les jeunes qui sont sexuellement actifs. La présente étude évalue si la confiance des partenaires prévoit l'utilisation du préservatif, et si les associations potentielles ont intervenu par l'auto-efficacité générale, parmi une cohorte d'adolescents sexuellement actifs dans le comté de Meru au Kenya. Nous avons également cherché à découvrir les associations entre la situation socioéconomique, la résilience et la confiance des partenaires pour augmenter la compréhension de confiance envers son partenaire sexuel. Les analyses de médiation, stratifiés selon le sexe, révèlent que l'utilisation du préservatif est prédite par l'auto-efficacité et la confiance des partenaires chez les femmes, mais pas chez les hommes. La résilience psychologique élevée prédit une faible confiance des partenaires chez les deux sexes. La confiance des partenaires était plus faible chez les femmes interrogées qui n'étaient pas alphabétisées, mais n'a pas varié de manière significative par rapport à l'alphabétisation chez les hommes. Les gains mensuels précédents déclarés ne sont pas significativement associés à la confiance des partenaires chez les hommes ou les femmes. Les présents résultats confirment une étude plus approfondie sur la confiance des partenaires, et son association avec les comportements sexuels de protection. En outre, les interventions ciblant l'utilisation du préservatif chez les femmes peuvent bénéficier de mesures visant à accroître la sensibilisation du comportement sexuel du partenaire et l'augmentation de l'auto-efficacité. (Afr J Reprod Health 2016; 20[2]: 94-103).

Mots-clés: utilisation du préservatif; auto-efficacité; orphelins et enfants vulnérables; Kenya

\section{Introduction}

In Kenya, the prevalence of HIV among adults aged $15-49$ years is $5.6 \%$. The prevalence has remained higher among women than men for the past decade, with an estimated difference of 2.7 percentage points in $2012^{1}$. A consequence of the high level of HIV prevalence and related mortality is a large number of children and youth who have lost one or both parents ${ }^{2}$ and are classified as orphan or vulnerable children
(OVC). Empirical evidence from across SubSaharan Africa (SSA) has shown that OVC status is a risk factor for increased sexual risk behavior, especially among females ${ }^{3,4}$. As transmission of HIV from an infected to a previously uninfected person occurs through the exchange of bodily fluids, sexual intercourse between sero-discordant partners increases risk of transmission. Sexual intercourse between HIV sero-discordant partners occurs with increased probability in a variety of social configurations: 
between older men and younger women ${ }^{3}$, professional sex workers and clients ${ }^{5}$, men who have sex with men ${ }^{6}$, and among people who have concurrent sex partnerships ${ }^{7}$. While people fitting these categories have been targeted by public health programs and policies in order to decrease HIV incidence, in Kenya most new HIV infections occur among heterosexual couples in a stable partnership ${ }^{8}$.

Committed sero-discordant partnerships either begin as discordant, or become so after the initiation of the relationship - most often through unfaithfulness by one of the partners who returns to the relationship with the virus contracted from a different partner (concurrency) ${ }^{9}$. A lively debate continues over the "concurrency hypothesis" - the theory that higher levels of HIV in SSA compared to other global regions can be explained by relatively higher levels of concurrency. While concurrency evidence does not explain why prevalence is higher in SSA compared to other regions, concurrent partnerships do significantly elevate risk of HIV and other undesirable outcomes among youth ${ }^{10}$. Recent survey data of married men in Kenya found that $10 \%$ reported at least one non-marital sexual partnership in the previous year, and $15.5 \%$ of all men reported concurrent partnerships in the previous year ${ }^{11}$. Women report significantly lower levels of concurrency $^{11}$.

The Kenyan Ministry of Health initiated its national condom policy in 2001 in an effort to reduce HIV transmission ${ }^{12}$, though as of 2012 the percentage of sexually active adults who used condoms with partners whose HIV serostatus was unknown is under $12 \%$ for men and under $5 \%$ for women ${ }^{11}$. The Kenyan government began incorporating insights from behavioral change theories to increase condom usage in $2007^{12}$. Perhaps as a consequence, the percentage of youth (aged 15-24 years) who reported using a condom at their first intercourse increased from $26.7 \%$ in 2007 to $62 \%$ in $2012^{11}$.

Among other behavioral change models, social cognitive theory has been used to understand and influence health behaviors including condom usage ${ }^{14}$. Social cognitive theory posits that there is a dynamic interaction between environmental factors, personal factors and human action ${ }^{15}$. Self-efficacy, a key feature of social cognitive theory, is a person's belief in their ability to set and attain meaningful goals. It directly corresponds to personal agency and is a proxy measure for motivation ${ }^{16}$. Individuals with more self-efficacy are better able to navigate their environments, making decisions that they find meaningful and affecting the sorts of change in their environments consistent with their beliefs and desires.

Self-efficacy has been evaluated as an essential component of negotiating safer sex practices in adolescent populations around the world $^{17}$. Self-efficacy has been found to mediate the relationship between intention to use condoms and actually using condoms among African American women, ${ }^{14}$ and South African adolescents $^{18}$ among other populations ${ }^{19,20}$. In order to increase the rates of condom usage among sexually active Kenyan OVC, it would be beneficial to further understand the association between self-efficacy and condom usage in this population.

Partner trust has recently been suggested as an important predictor of condom usage among young adults in Tanzania ${ }^{21}$. Young adults who trust the sexual fidelity of their partner have been found to use condoms less frequently than young adults who do not trust their partner's sexual fidelity. The construct of partner trust is important as a potential summative measure of risk perception across myriad social configurations that may increase risk of sexually transmitted infections, although the suggestion of condom use among ostensibly committed relationships is challenging. Married individuals tend to report higher levels of partner trust ${ }^{19}$ and suggestions that partnerships include condom usage may compromise relationships by insinuating distrust ${ }^{22}$. However, developing trust within a relationship requires communication and shared power ${ }^{23}$ and these are also prerequisites of negotiating condom usage ${ }^{24}$. Additionally, a prior history of casual sexual partners among some populations predict higher levels of unprotected intercourse ${ }^{26}$, adding to the uncertainty about the potential use of partner trust as a predictor of condom usage. While partner trust may alleviate concerns about the risks of unprotected sex in some relationships, it may be a prerequisite to negotiating condom usage in others.

Social psychology has used "identity theory" to explore the reciprocal nature of selfverification and other-verification within the context of committed relationships ${ }^{26}$. According to identity theory, development of commitment emerges from a dynamic process of building trust between one's self and one's partner. As an intimate partner provides affirmation of one's 
Figure 1: Flow Chat from Whole Sample to Sub-Sample Used in Present Analysis

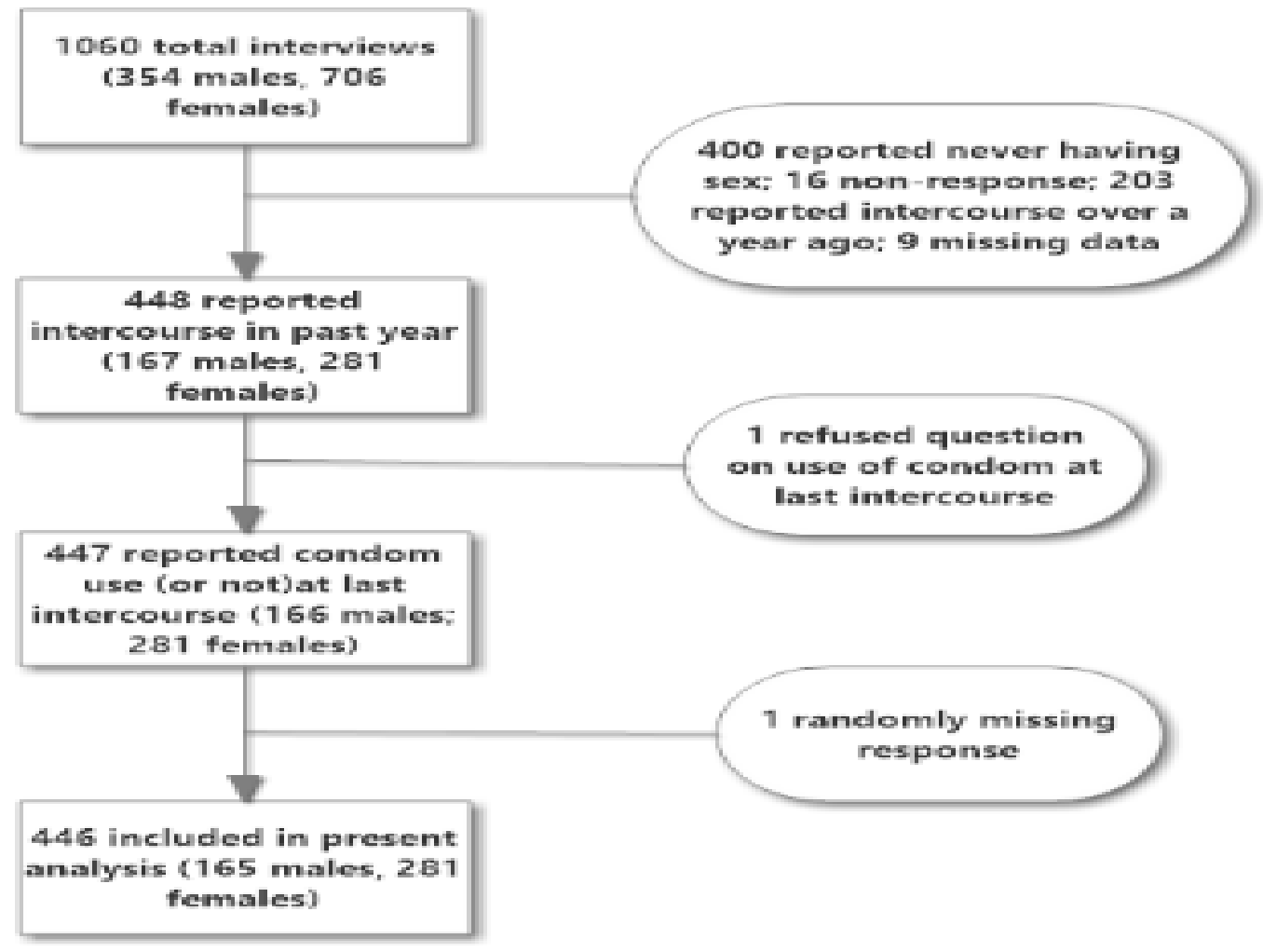

own self-view, one develops trust of the partner, increasing evaluation of one's self and one's partner. Within this dynamic context, trust of partner reinforces trust of one's self and builds relationship commitment. Condom usage can be a reflection of relationship commitment among sexually active adolescents ${ }^{27}$. Synthesizing insights from social-cognitive theory, wherein self-efficacy is an affirmation of one's potential to keep commitments and affect change, and identity theory, wherein affirmation of one's self is partially a reflection of trusting relationships, a relatively unexplored question regarding condom-usage emerges as to whether selfefficacy mediates the association between partner trust and condom usage. In addition to self-efficacy, psychological resilience is another important potential psychosocial determinant of sexual risk behaviors ${ }^{28}$.

While orphans and vulnerable children are at a higher risk of a range of sexual risk behaviors $^{29}$, psychological resilience has been shown to protect against exposure to such risks.

Prior research has not fully explored whether psychological resilience is associated with partner choice among sexually active orphans and vulnerable youth.

The present study describes condom usage at last intercourse among sexually active adolescents from a sample of 1,060 OVC interviewed in Meru County, Kenya in March 2014. Further, we assess if condom usage is predicted by whether respondents trusted their most recent sex partner to not have a concurrent partner, and whether found associations are mediated by self-efficacy. Finally, we assess whether psychological resilience predicts whether respondents trusted the faithfulness of their most recent partner.

\section{Methods}

\section{Study design}

The study analyzed secondary data collected in a cross-sectional evaluation of participants in a three year community-based empowerment program targeting OVC in Meru County, Kenya. Previous studies have described the program model in greater detail ${ }^{29}$. Data were collected using a structured interview schedule administered by trained interviewers who were also participants in the program. Figure 1 shows the flow of total respondents to respondents included in the present analysis.

\section{Participants}

Study participants were older siblings of OVC families, actively representing their family in the 
three year program. The study program was segmented into 12 different regions, with each region meeting once per month. Data were collected at a monthly regional meeting by trained interviewers over the age of 18 years who were also participants in the program. Interviewers did not conduct interviews at regional locations that were adjacent to their own home region, so as to limit the risk of social desirability bias. All program participants who came to a regional meeting were invited to participate in the study. All participants were informed that their participation was voluntary and would not lead to personal punishment or reward. There were 1,060 participants who provided informed consent and were interviewed and 2 abstained. Of the 1,060 original participants (66.6\% female), only 419 met the criteria for the present analysis (64.6\% female).

The primary mechanisms by which the program operates are through psychosocial support, health, hygiene and livelihood education and household economic strengtheningpromoting income generating activities, job training, and small grant transfers. The survey was administered in Kimeru, the local language, following review of an English-Kimeru-English translation process.

\section{Measures}

Condom usage at last intercourse was recorded using a single binary item. Only respondents who indicated they were sexually active in the previous year were included in the analysis $(\mathrm{n}=148$ males, 271 females). Self-efficacy was recorded using the 4-point, Likert-type 10-item general self-efficacy scale ${ }^{30}$ and found to have acceptable reliability $(\Omega=0.69)^{31}$. Example scale items are: "I can always manage to solve difficult problems if I try hard enough," "It is easy for me to stick to my aims and accomplish my goals," and "If I am in trouble, I can usually think of a solution." The scale was calculated using average item response for a range of 0-4.

Psychological resilience was measured using the 25-item, 7-point Likert-type scale by Wagnild (RS-25) ${ }^{32}$. The scale uses items like "I seldom wonder what the point of it all is" to assess one's ability to bounce back from adversity and positively adapt to new situations. Partner trust was evaluated on a 5-point Likerttype scale following the question "how much do you trust that your most recent intercourse partner did not have intercourse with someone else around the time she or he had intercourse with you?" Five was indicated as "complete trust" and 1 was indicated as "complete distrust." In statistical analysis, the measure was binarized to include "complete trust" and "less than complete trust." The most extreme distrust value on the 5-point Likert-type scale was combined with "uncertain" responses to produce the binary indicator " 1 ," and less than the most extreme distrust value was coded as " 0 ." The choice to use a binary cutpoint was motivated by a desire to increase statistical power, and the choice to include "uncertain" responses as most extreme was driven by an interest in taking the most conservative approach to account for potential misclassification bias.

\section{Data analysis}

Three main questions guided the analysis:

1. Did respondents with higher psychological resilience report lower probabilities of engaging in sexual intercourse with untrusted partners? Resilience theory suggests that psychological resilience should protect vulnerable individuals from harmful actions ${ }^{33}$, such as engaging in intercourse with untrusted partners.

2. Does suspicion of other sexual partners increase the odds of using a condom with your most recent sexual partner?

3. Does self-efficacy mediate any association between trust in partner fidelity and condom usage?

In each of these questions, the outcome variable is a binary measure. Logistic regression models were used to assess the association between resilience and partner trust, the association between partner trust and condom usage and the associations between partner trust, self-efficacy and condom usage ${ }^{34}$. All pathways control for age and reported monthly income. All descriptive and inferential statistics were stratified by gender, following insights from previous research indicating there are gendered differences with respect to sexual behavior, pathways and outcomes ${ }^{35}$. Descriptive statistics were used to profile condom use, degree of partner trust, self-efficacy, and all covariates used to predict partner trust with appropriate tests of differences used to compare males to females within the population. Appropriate tests of fit were applied to each model and included in their corresponding table. All confidence 
Table 1: Key Characteristics of Respondents, by Gender and Condom Usage at Last Sex

\begin{tabular}{|c|c|c|c|c|}
\hline \multicolumn{4}{|c|}{ Females, no condom at last sex $(n=133,47.3 \%)$} & \multirow[t]{2}{*}{ Test statistic $(p)$} \\
\hline & Mean (\%) & $95 \% \mathrm{Cl}$ & & \\
\hline Partner distrust & $75.9 \%$ & $68.6 \%$ & $83.3 \%$ & \\
\hline Self-efficacy & 3.032 & 2.937 & 3.127 & \\
\hline Psychological resilience & 5.252 & 5.125 & 5.379 & \\
\hline Age (yrs) & 18.902 & 18.496 & 19.307 & \\
\hline Monthly income (\$) & 15.483 & 12.654 & 18.313 & \\
\hline \multicolumn{5}{|c|}{ Females, condom at last sex $(n=148,52.7 \%)$} \\
\hline & Mean (\%) & $95 \% \mathrm{Cl}$ & & \\
\hline Partner distrust & $52.9 \%$ & $43.1 \%$ & $62.6 \%$ & $6.18(0.013)$ \\
\hline Self-efficacy & 3.308 & 3.222 & 3.394 & $-5.77(<0.001)$ \\
\hline Psychological resilience & 5.687 & 5.558 & 5.815 & $-5.496(<0.001)$ \\
\hline Age (yrs) & 18.854 & 18.456 & 19.253 & $-1.51(0.132)$ \\
\hline Monthly income (\$) & 18.177 & 14.757 & 21.597 & $-1.04(0.3)$ \\
\hline \multicolumn{5}{|c|}{ Males, no condom at last sex $(n=61,37 \%)$} \\
\hline Partner distrust & 0.557 & 0.429 & 0.686 & \\
\hline Self-efficacy & 3.189 & 3.063 & 3.314 & \\
\hline Psychological resilience & 5.492 & 5.347 & 5.636 & \\
\hline Age (yrs) & 18.443 & 17.85 & 19.035 & \\
\hline Monthly income (\$) & 16.143 & 12.949 & 19.336 & \\
\hline \multicolumn{5}{|c|}{ Males, condom at last sex $(n=104,63 \%)$} \\
\hline Partner distrust & $62.2 \%$ & $54.3 \%$ & $70.1 \%$ & $0.126(0.723)$ \\
\hline Self-efficacy & 3.317 & 3.25 & 3.383 & $-2.15(0.033)$ \\
\hline Psychological resilience & 5.694 & 5.595 & 5.792 & $-1.93(0.056)$ \\
\hline Age (yrs) & 19.318 & 18.952 & 19.683 & $-1.19(0.237)$ \\
\hline Monthly income (\$) & 17.736 & 14.565 & 20.907 & $-0.8(0.425)$ \\
\hline
\end{tabular}

intervals for regression and mediation analyses were bootstrapped with 500 replicates. Data were entered into EpiInfo v.7 and analyzed with STATA v.13 using the "binary mediation" adds on procedure (Phil Ender, UCLA Academic Technology Service).

\section{Ethical considerations}

All participants provided informed consent, indicating they understood there would be no personal benefit or punishment for abstaining or participating. Ethical review was provided by the Committee for the Protection of Human Subjects at the University of Texas Health Science Center for the evaluation of program collected data.

\section{Results}

Descriptive data on the 446 respondents included in the sample are provided in Table 1. Females had higher distrust of their partners than did males; also, females had generally lower resilience and self-efficacy than did males. Respondents who used condoms at last intercourse tended to be older, but not at a level of statistically significance. Males reported higher monthly income than did females. Age and monthly income did not differ significantly between condom users and non-users when stratified by gender. Partner distrust was significantly higher among females who did not use condoms at last intercourse than among females who did use condoms at last intercourse. Psychological resilience was higher among condom users in both genders than among noncondom users.

Table 2 shows the results of the mediation analysis of the association between partner trust and condom usage among females. The odds ratios for each pathway, plus the path 
Table 2: Partner Distrust and Condom Usage, Mediated by Self-Efficacy among Females ( $\mathrm{n}=277$ )

\begin{tabular}{|c|c|c|c|}
\hline \multicolumn{4}{|c|}{ Logistic regression of partner distrust on psychological resilience } \\
\hline Resilience $->$ partner distrust & OR & $95 \% \mathrm{Cl}$ & \\
\hline Psychological resilience & $0.364 * * *$ & 0.235 & 0.563 \\
\hline Age (yrs) & 0.951 & 0.847 & 1.068 \\
\hline Monthly income & 0.996 & 0.982 & 1.011 \\
\hline Likelihood Ratio Chi^2 (p) & $26.67(<0.001$ & & \\
\hline Goodness of Fit Chi^2 (p) & $252.16(0.46$ & & \\
\hline \multicolumn{4}{|c|}{ Partner distrust -> condom usage (c path, logit) } \\
\hline & OR & $95 \% \mathrm{Cl}$ & \\
\hline Partner trust & $0.545 *$ & 0.323 & 0.919 \\
\hline Age (yrs) & 1.058 & 0.951 & 1.177 \\
\hline Monthly income & 1.006 & 0.992 & 1.019 \\
\hline Likelihood Ratio Chi^2 (p) & $7.83(0.05)$ & & \\
\hline Goodness of Fit Chi^2 (p) & $136.29(0.35$ & & \\
\hline \multicolumn{4}{|c|}{ Partner distrust $->$ self-efficacy (a path, OLS) } \\
\hline & Coef. & $95 \% \mathrm{Cl}$ & \\
\hline Partner trust & $-0.339 * * *$ & -0.461 & -0.218 \\
\hline Age (yrs) & 0.013 & -0.012 & 0.038 \\
\hline Monthly income & 0.001 & -0.002 & 0.004 \\
\hline ANOVA F (p) & $11.11(<0.00$ & & \\
\hline$R^{\wedge} 2$ & 0.109 & & \\
\hline \multicolumn{4}{|c|}{ Partner trust $->$ self-efficacy $->$ condom usage (b and c' paths, logit) } \\
\hline Partner distrust & 0.787 & 0.448 & 1.387 \\
\hline Self-efficacy & $3.183 * * *$ & 1.843 & 5.497 \\
\hline Age (yrs) & 1.048 & 0.938 & 1.17 \\
\hline Monthly income & & 0.304 & $<0.001$ \\
\hline \multicolumn{2}{|l|}{ Likelihood Ratio Chi^2 (p) } & $.57(<0$. & \\
\hline Goodness of Fit Chi^2 (p) & & $4.76(0$. & \\
\hline \multicolumn{2}{|c|}{ Path coefficient } & \multicolumn{2}{|c|}{$95 \% \mathrm{Cl}$} \\
\hline Indirect effect $(a * b)$ & -0.096 & -0.158 & -0.05 \\
\hline Direct effect $\left(c^{\prime}\right)$ & -0.058 & -0.196 & 0.082 \\
\hline Total effect $(a * b)+c^{\prime}$ & -0.153 & -0.283 & -0.021 \\
\hline \multicolumn{2}{|c|}{ \% total effect mediated by self-efficacy } & \multicolumn{2}{|c|}{$62.75 \%$} \\
\hline \multicolumn{2}{|c|}{$\%$ total effect not mediated by self-efficacy } & \multicolumn{2}{|c|}{$37.91 \%$} \\
\hline \multicolumn{4}{|c|}{$\begin{array}{c}\text { Notes: regression models show association between psychological } \\
\text { resilience, partner distrust, self-efficacy and condom usage. * indicates } \\
\mathrm{p}<0.05 ; * * \mathrm{p}<0.01 ; * * * \mathrm{p}<0.001 \text {. Foud different serial models are presented. } \\
\text { In each case, the type of regression is shown in parentheses above the } \\
\text { coefficients/odds ratios. }\end{array}$} \\
\hline
\end{tabular}

coefficients, are provided along with 95\% confidence intervals. Females with higher psychological resilience were less likely to engage with sex partners they did not trust (OR: 0.36 , 95\% CI: 0.235-0.563). For each increase in the 7-point scale average of resilience, the odds that the respondent engaged in sex with an untrusted partner decreased 64\%. Before taking self-efficacy into account, females who most distrusted their last partner had lower odds of reporting condom usage at last sex event (OR: 0.545, 95\%CI: 0.323-0.919). Females who reported less trusting partnerships had significantly lower levels of self-efficacy $(-0.339$, 95\%CI: $-0.461,-0.218)$. Self-efficacy explained $63 \%$ of the total effect of partner distrust on condom usage at last sex. For each increase in the 4-point scale average of selfefficacy, the odds that the respondent used a condom at last sex more than tripled (OR: 3.18, 95\% CI: 1.84-5.5).

Table 3 shows the results of the mediation analysis of the association between partner trust and condom usage among males. Males with higher psychological resilience were significantly less likely to engage in intercourse with partners they did not trust (OR: 0.48, 95\% CI: 0.28-0.83). Higher age and more monthly income also showed associations at or near significance. Partner distrust did not predict 
Table 3: Partner Distrust and Condom Usage, Mediated by Self-Efficacy among Males ( $\mathrm{n}=153)$

\begin{tabular}{|c|c|c|c|}
\hline \multicolumn{4}{|c|}{ Logistic regression of partner distrust on psychological resilience } \\
\hline Resilience -> partner distrust & OR & $95 \% \mathrm{Cl}$ & \\
\hline Psychological resilience & $0.481 * *$ & 0.278 & 0.933 \\
\hline Age (yrs) & $0.851 *$ & 0.723 & 1 \\
\hline Monthly income & $0.979^{t}$ & 0.957 & 1.001 \\
\hline Likelihood Ratio Chi^2 (p) & $16.73(<0.001$ & & \\
\hline Goodness of Fit Chi^2 (p) & $151.6(0.337)$ & & \\
\hline \multicolumn{4}{|c|}{ Partner distrust $->$ condom usage (c path, logit) } \\
\hline & OR & $95 \% \mathrm{Cl}$ & \\
\hline Partner trust & 0.303 & 0.457 & 1.736 \\
\hline Age (yrs) & 1.067 & 0.911 & 1.25 \\
\hline Monthly income & 1.007 & 0.985 & 1.03 \\
\hline Likelihood Ratio Chi^2 (p) & $1.54(0.673)$ & & \\
\hline Goodness of Fit Chi^2 (p) & $100.26(0.238$ & & \\
\hline \multicolumn{4}{|c|}{ Partner distrust -> self-efficacy (a path, OLS) } \\
\hline & Coef. & $95 \% \mathrm{Cl}$ & \\
\hline Partner trust & $-0.191 * * *$ & -0.337 & -0.045 \\
\hline Age (yrs) & 0.01 & -0.024 & 0.044 \\
\hline Monthly income & 0.003 & -0.002 & 0.007 \\
\hline ANOVA F $(p)$ & $3.44(0.018)$ & & \\
\hline $\mathrm{R}^{\wedge} \mathbf{2}$ & 0.063 & & \\
\hline \multicolumn{4}{|c|}{ Partner trust $->$ self-efficacy $->$ condom usage (b and c' paths, logit) } \\
\hline & OR & $95 \% \mathrm{Cl}$ & \\
\hline Partner distrust & 1.005 & 0.505 & 2.001 \\
\hline Self-efficacy & 1.846 & 0.894 & 3.811 \\
\hline Age (yrs) & 1.06 & 0.903 & 1.244 \\
\hline Monthly income & 1.006 & 0.983 & 1.029 \\
\hline Likelihood Ratio Chi^2 (p) & \multicolumn{3}{|c|}{$4.31(0.366)$} \\
\hline Goodness of Fit Chi^2 (p) & \multicolumn{3}{|c|}{$147.64(0.423)$} \\
\hline \multicolumn{2}{|c|}{ Path coefficient } & \multicolumn{2}{|c|}{$95 \% \mathrm{Cl}$} \\
\hline Indirect effect $(a * b)$ & -0.003 & -0.058 & 0.057 \\
\hline Direct effect $\left(c^{\prime}\right)$ & 0.188 & -0.011 & -0.362 \\
\hline Total effect $(a * b)+c^{\prime}$ & 0.185 & 0.002 & 0.351 \\
\hline \multicolumn{2}{|c|}{ \% total effect mediated by self-efficacy } & $N / A$ & \\
\hline \multicolumn{2}{|c|}{$\%$ total effect not mediated by self-efficacy } & N/A & \\
\hline \multicolumn{4}{|c|}{$\begin{array}{c}\text { Notes: regression models show association between psychological } \\
\text { resilience, partner distrust, self-efficacy and condom usage. }{ }^{t} \text { indicates } \\
\mathrm{p}<0.01 ; * \mathrm{p}<0.05 ; * * \mathrm{p}<0.01 ; * * * \mathrm{p}<0.001 . \text { Foud different serial models are } \\
\text { presented. In each case, the type of regression is shown in parentheses } \\
\text { above the coefficients/odds ratios. }\end{array}$} \\
\hline
\end{tabular}

condom usage among males, though partner distrust did predict lower self-efficacy. Because there were no direct, indirect or total effects of partner distrust on condom usage, effects could not be decomposed.

\section{Discussion}

This analysis evaluated whether intercourse partner trust - defined as the degree of one's belief that the partner was not sexually engaged with another person around the time of most recent intercourse - predicted condom usage at most recent intercourse, and whether any observed association was mediated by general self-efficacy among OVC females and males in Meru County, Kenya. OVC, especially female OVC, have been found to have higher rates of sexual risk behaviors and related adverse outcomes than non-OVC ${ }^{3,4}$. In the context of a mature HIV endemic, understanding determinants of condom usage is important and 
will have implications for policy and research targeting the reduction of HIV transmission and other adverse sex outcomes.

Partner trust significantly predicted condom usage among females but not males in our sample ( $\mathrm{n}=271$ females, 148 males). Just over $30 \%$ of the observed pathway among females was mediated by general self-efficacy. To evaluate directionality of the pathway in further analysis, self-efficacy was set as the independent variable and partner trust as the mediating variable (not shown). Further analysis demonstrated that partner trust did not mediate the pathway between self-efficacy and condom usage among females. Partner trust was associated with general self-efficacy among males, with higher partner trust predicting lower self-efficacy.

Females who distrusted their last sexual partner had significantly lower odds of reporting that a condom was used at that occurrence. This association was almost entirely mediated by selfefficacy. It is interesting that among males, selfefficacy is also higher among respondents who trusted their last sexual partner. Data suggest that investigating the dynamic between confidence in one's partner, and confidence in one's own ability, may be intertwined. Among females, greater self-belief predicted condom usage, suggesting that the security women feel in the context of sexual relationships may increase their ability to negotiate condom usage. Programs that target relationship dynamics among sexually active adolescents may be able to foster increased confidence between partners, and thereby promote the relationship dynamics required to negotiate safer sex. Self-efficacy may be influenced not only by the quality of outside programs, but also by the quality of interpersonal relationships.

With both male and female respondents, higher psychological resilience predicted lower probability of engaging in intercourse with an untrusted partner. Psychological resilience is a complex phenomenon that only recently has begun to be explored among OVC in subSaharan Africa ${ }^{36}$. Further research and program evaluation may reveal mechanisms to increase psychological resilience among youth in this population, potentially driving safer partner choices.

In sum, the present findings suggest a complex nature of the dynamics of partner trust and condom usage. Resilience may improve selection of sexual partners by decreasing the probability of engaging in intercourse with partners engaged in concurrent sexual behavior. Self-efficacy may be a feature of more committed sexual partnerships, where the ability to negotiate condom usage is paradoxically more feasible but less necessary for sexual health.

\section{Limitations}

There are many limitations with this study. Partner trust has been evaluated elsewhere in sub-Saharan Africa ${ }^{27}$, where it was found to have the opposite association to the one found in the present study. Slight changes in definition or population characteristics may be responsible for the difference. It is logical that respondents with greater trust of the their partner would be more willing to engage in intercourse without the use of condoms; it is also logical that commitment and trust are requirements to negotiate the ability to use condoms within a sexual partnership. Further research on the different conceptualizations of trust, and the characteristics contributing to perceptions of partner fidelity and the behavioral consequences of those perceptions, are required.

It is possible that respondents with higher self-efficacy were more likely to express doubt about their partner's sexual fidelity, more likely to admit doubts to themselves or more likely to investigate the nature of their partner's sexual relationship with other people.

All data were cross-sectional, precluding some interpretation of directionality. As mentioned above, partner trust did not mediate the association between self-efficacy and condom usage, supplying support to the given interpretation. The questionnaire included psychosocial measures before sex behavior questions, and it is possible that higher selfefficacious and resilient individuals were drawn to consider their effectiveness at goal setting, such as condom usage and engaging with reliable sex partners.

The study was questionnaire based, and conducted by peers. The possibility of social response bias - providing only socially acceptable answers - is a potential threat to validity. Individuals with more coping skills may be more inclined to present themselves in a socially favorable manner. Given that more resilient and self-efficacious individuals reported partner trust, presumably a social value, at a 
significantly lower level, it is possible that social response bias did not meaningfully influence responses.

\section{Further study}

The present study suggests an interesting new direction in behavioral interventions to promote condom use on local and national levels. Partner trust warrants more evaluation before it can be widely adopted as an important tool in the effort to promote condom usage. Using longitudinal data to assess and record changes in partner status may help validate the measure. In addition to further validating the measure, assessing whether interventions can influence partner trust and self-efficacy, with endpoints of regular condom usage, HIV incidence and other unwanted sex outcomes would be helpful.

\section{Conclusion}

Understanding factors predicting condom usage among sexually active youth in high HIV prevalent countries is essential to improving condom usage and decreasing incidence of HIV and other consequences of risky sex. The present study evaluated the association between condom usage and partner trust, as mediated by general self-efficacy, among 281 sexually active female adolescents and 165 sexually-active male adolescents in Meru County, Kenya. We found females with lower levels of partner trust reported lower odds of condom usage at last intercourse, but there was no such association among males. Further, lower general selfefficacy accounted for approximately $63 \%$ of the total effect among females. Further study is required to clarify these associations, but the findings are relevant for programs aimed at increasing self-efficacy and increased awareness of partner behavior among females in the population to promote condom usage.

\section{Declaration}

MG led the design and implementation of the study, and wrote the majority of the manuscript. SH conducted data analysis and interpretation. SG facilitated data collection and helped design the study. PK provided manuscript review and editing. LRG facilitated data interpretation and discussion, and directed the project. All authors approve of the final manuscript.

\section{References}

1. Kimanga DO, Umuro, M, Ng'ang'a A, Kimondo L, Murithi P, Muttunga J, Waruiru W, Mohammed I, Sharrif S, De Cock KM, and Kim AA. Prevalence and incidence of HIV infection, trends, and risk factors among persons aged 15-64 years in Kenya: results from a nationally representative study. JAIDS 2014; 66: S13-S26.

2. Puffer ES, Drabkin AS, Stashko AL, Broverman SA, Ogwang-Odhiambo RA, and Sikkema KJ. Orphan status, HIV Risk behavior, and mental health among adolescents in rural Kenya. J Pediatr Psychol 2012; 37(8): 868-878.

3. Cluver L, Orkin M, Boyes M, Gardner F, and Meinck F. Transactional sex amongst AIDS-orphaned and AIDS-affected adolescents predicted by abuse and extreme poverty. JAIDS. 2011; 58(3):336343.

4. Birdthistle IJ, Floyd S, Machingura A, Mudziwapasi $\mathrm{N}$, Gregson S, and Glynn JR. From affected to infected? Orphanhood and HIV risk among female adolescents in urban Zimbabwe. AIDS 2008; 22(6):759-766.

5. Odek WO, Busza J, Morris CN, Cleland J, Ngugi EN, and Ferguson AG. Effects of micro-enterprise services on HIV risk behaviour among female sex workers in Kenya's urban slums. AIDS Behav. 2009; 13(3): 449-461.

6. Sanders EJ, Graham SM, Okuku HS, van der Elst EM, Muhaari A, Davies A, Peshu N, Price M, McClelland RS, and Smith AD. HIV-1 infection in high risk men who have sex with men in Mombasa, Kenya. Aids 2007; 2(18): 2513-2520.

7. Mah TL and Halperin DT. Concurrent sexual partnerships and the HIV epidemics in Africa: evidence to move forward. AIDS Behav 2010; 14(1): 11-16

8. Gouws E and Cuchi P. Focusing the HIV response through estimating the major modes of HIV transmission: a multi-country analysis. Sex. Transm. Infect. 2012; 88(Suppl 2): i76-i85.

9. Sawers L. Measuring and modelling concurrency. J Int AIDS Soc. 2013; 16(1).

10. Doyle AM, Mavedzenge SN, Plummer ML, and Ross DA. The sexual behaviour of adolescents in sub-Saharan Africa: patterns and trends from national surveys. Trop Med Int Health 2012; 17(7): 796-807.

11. Maina WK, Kim AA, Rutherford GW, Harper M, K'Oyugi BO, Sharif S, Kichamu G, Maraguri NM, Akhwale W, and De Cock KM. Kenya AIDS indicator surveys 2007 and 2012: implications for public health policies for HIV prevention and treatment. JAIDS 2014; 66: S130S137.

12. National AIDS Control Council (NACC). National Condom Policy and Strategy, 2001-2005. Nairobi, Kenya: NACC; 2001.

13. National AIDS Control Council (NACC). Kenya AIDS Epidemic: Update 2011. Nairobi, Kenya: NACC; 2012.

14. O'Leary A, Jemmott LS, and Jemmott JB, 3rd. Mediation Analysis of an Effective Sexual Risk- 
Reduction Intervention for Women: The Importance of Self-Efficacy. Health Psych 2008; 27(S2); S180-S184.

15. Bandura A. Social cognitive theory: An agentic perspective. Annu Rev Psychol 2001; 52(1): 1-26.

16. Bandura A. Human agency in social cognitive theory. Am Psychol 1989; 44(9): 1175-1184.

17. Buhi ER and Goodson P. Predictors of adolescent sexual behavior and intention: A theory-guided systematic review. J Adolesc Health 2007; 40(1): 4-21.

18. O'Leary A, Jemmott JB, 3rd, Jemmott LS, Bellamy S, Ngwane Z, Icard L, and Gueits L. Moderation and mediation of an effective HIV risk-reduction intervention for South African adolescents. Ann Behav Med 2012; 44(2): 181-191.

19. Jemmott LS and Jemmott JB, 3rd. Increasing condom-use intentions among sexually active black adolescent women. Nurs Rev. 1992; 13(6):512-9.

20. Schmiege SJ, Broaddus MR, Levin M, and Bryan AD. Randomized trial of group interventions to reduce HIV/STD risk and change theoretical mediators among detained adolescents. J Consult Clin Psychol. 2009; 77(1):38-50.

21. Hattori MK. Trust and condom use among young adults in relationships in Dar es salaam, Tanzania. J Biosoc Sci 2014; 46(5): 1-18.

22. Klein M and Coombes Y. Trust and Condom Use: The Role of Sexual Caution and Sexual Assurances for Tanzanian Youth (a Baseline Survey). PSI Working Paper Series (\#64) 2005.

23. Lock S, Ferguson S, Wise C, Kennedy C, Anderson N, Heineken J. Communication of Sexual Risk Behavior among Late Adolescents. Western Journal of Nursing Research. 1998;20(3):273294. doi:10.1177/019394599802000302.

24. Montgomery C, Lees S, Stadler J et al. The role of partnership dynamics in determining the acceptability of condoms and microbicides. AIDS Care. 2008;20(6):733-740. doi:10.1080/095 401 20701693974.

25. Zablotskae IB, Grulich AE, DeWit J, and Prestage G. Casual sexual encounters among gay men: familiarity, trust and unprotected anal intercourse. AIDS Behav, 2011;15(3):607-612.

Behavior Among Young Carers in the Context
26. Burke P, Stets J. Trust and Commitment through SelfVerification. Soc Psychol Q. 1999;62(4):347. doi: $10.2307 / 2695833$.

27. Bauman L, Berman R. Adolescent Relationships and Condom Use: Trust, Love and Commitment. AIDS Behav. 2005;9(2):211-222. doi:10.1007/s 10461-005-3902-2.

28. Masten AS. Ordinary magic: Resilience processes in development. Am. Psychol. 2001; 56(3): 227.

29. Goodman M, Selwyn B, Morgan R et al. Sexual a Kenyan Empowerment Program Combining Cash-Transfer, Psychosocial Support, and Entrepreneurship. J Sex Res. 2015:1-15. doi:10.1080/00224499.2015.1035429.

30. Schwarzer R, and Jerusalem M. Generalized SelfEfficacy scale. In: Weinman J, Wright S, and Johnston M (Ed.). Measures in health psychology: A user's portfolio. Causal and control beliefs. Windsor, UK: NFER-Nelson, 1995, 35-37.

31. Revelle W and Zinbarg RE. Coefficients alpha, beta, omega, and the glb: Comments on Sijtsma. Psychometrika 2009; 74(1): 145-154.

32. Wagnild GM, Young HM. Development and psychometric evaluation of the Resilience Scale. J Nurs Meas 1993; 2:165-78.

33. Goodman M, Lloyd L, Selwyn B et al. Factors associated with general self-efficacy and resilience among youth heads of households in Kenya. Journal of Health Psychology. 2015. doi:10.1177/1359105315573443.

34. VanderWeele TJ and Vansteelandt S. Odds ratios for mediation analysis for a dichotomous outcome. Am J Epidemiology 2010: 172(12); 1339-1348.

35. Namisi FS, Aarø LE, Kaaya S, Onya HE, Wubs A, and Mathews C. Condom use and sexuality communication with adults: a study among high school students in South Africa and Tanzania. BMC public health 2013; 13(1): 874.

36. Li X, Chi P, Sherr L, Cluver L, Stanton B. Psychological resilience among children affected by parental HIV/AIDS: a conceptual framework. Health Psychology and Behavioral Medicine. 2015;3(1):217-235. doi:10.1080/21642850 .2015. 1068698 . 